\title{
Pengaruh Ekstrak Daun Nerium oleander L. terhadap Mortalitas dan Perkembangan Hama Spodoptera litura Fab.
}

\author{
Effects of Nerium oleander L. Leaf Extract on Mortality and Development of Pests \\ Spodoptera litura Fab.
}

\section{Heri Prabowo}

Balai Penelitian Tanaman Tembakau dan Serat

Jl. Raya Karangploso Km 4 Kotak Pos 199, Malang, Jawa Timur

E-mail: heri_prabowo@yahoo.com

\begin{abstract}
Research was conducted at the Laboratory of Entomology, Tobacco and Fiber Crops Research Center from June to July 2009. Tests were conducted on the larvae of Spodoptera litura second instar. Concentration of leaf extract of $N$. oleander used was $0 ; 2 \times 10^{5} ; 3 \times 10^{5} ; 4 \times 10^{5}$; and $5 \times 10^{5} \mathrm{ppm}$. Treatment was done by spraying method in the spray chamber. Treatment was arranged in a completely randomized design (RAL) with 4-time repetition. Each repetition used 25 larvae. Observed parameters included the death for every 24, 48, 72, and 96 hours; length, width, and weight of larvae after 96 hours after treatment. By 96 hours after treatment with the concentration of leaf extract $0 ; 2 \times 10^{5} ; 3 \times 10^{5} ; 4 \times 10^{5}$; and $5 \times 10^{5} \mathrm{ppm}$ it was capable of causing mortality $S$. litura, respectively for $0 ; 48.33 ; 53.33 ; 66.67 \%$, dan $76.67 \%$. By 96 hours after treatment extract concentration required to cause mortality $S$. litura was 25,50 , and $95 \%$ respectively of $2.35 \times 10^{5}, 4.44 \times 10^{5}$, and $9.49 \times 10^{5} \mathrm{ppm}$. After 96-hour treatment the concentration of leaf extract $0 ; 2 \times 10^{5} ; 3 \times 10^{5} ; 4 \times 10^{5}$; and $5 \times 10^{5} \mathrm{ppm}$ could cause the length, width, and weight of S. litura, respectively for $0.89 \mathrm{~mm} ; 0.91 \mathrm{~mm} ; 0.93 \mathrm{~mm} ; 0.94 \mathrm{~mm} ; 0.95 \mathrm{~mm} ; 0.15 \mathrm{~mm} ; 0.16 \mathrm{~mm}$; $0.17 \mathrm{~mm} ; 0.18 \mathrm{~mm} ; 0.19 \mathrm{~mm}, 0.011 \mathrm{~g} ; 0.012 \mathrm{gr} ; 0.013 \mathrm{~g} ; 0.014 \mathrm{~g}$ and $0.016 \mathrm{gr}$. The use of $N$. oleander leaf extract caused mortality of $S$. litura between $13.33-76.67 \%$ at 24 to 96 hours after treatment. Leaf extract of $N$. oleander potentially caused mortality $S$. litura. The use of this leaf extract could also inhibit the length, width, and weight of larvae.
\end{abstract}

Key words: Nerium oleander leaf extract, mortality, length, width, weight, Spodoptera litura

\section{Abstrak}

Penelitian dilaksanakan di Laboratorium Entomologi Balai Penelitian Tanaman Tembakau dan Serat mulai bulan Juni sampai Juli 2009. Pengujian dilakukan terhadap larva $S$. litura instar dua. Konsentrasi ekstrak daun $N$. oleander yang digunakan adalah $0 ; 2 \times 10^{5} ; 3 \times 10^{5} ; 4 \times 10^{5}$; dan $5 \times 10^{5} \mathrm{ppm}$. Perlakuan dilakukan dengan metode penyemprotan di dalam spray chamber. Perlakuan disusun dalam rancangan acak lengkap (RAL) dengan ulangan 4 kali. Tiap-tiap ulangan digunakan sebanyak 25 ekor larva. Parameter yang diamati antara lain kematian setiap 24, 48, 72, dan 96 jam; panjang, lebar, dan berat larva setelah 96 jam setelah perlakuan. Pada 96 jam setelah perlakuan ekstrak daun dengan konsentrasi $0 ; 2 \times 10^{5} ; 3 \times 10^{5} ; 4 \times 10^{5}$; dan $5 \times 10^{5}$ ppm mampu menyebabkan mortalitas $S$. litura berturut-turut sebesar $0 ; 48,33 ; 53,33$; 66,67\%; dan 76,67\%. Pada 96 jam setelah perlakuan konsentrasi ekstrak yang dibutuhkan untuk menyebabkan mortalitas $S$. litura 25,50 , dan $95 \%$ berturut-turut sebesar $2,35 \times 10^{5}$, $4,44 \times 10^{5}$, dan 9,49x10 $\mathrm{ppm}$. Setelah 96 jam setelah perlakuan ekstrak daun dengan konsentrasi $0 ; 2 \times 10^{5} ; 3 \times 10^{5} ; 4 \times 10^{5}$; dan $5 \times 10^{5} \mathrm{ppm}$ mampu menyebabkan panjang, lebar, dan berat larva $S$. litura berturut-turut sebesar $0,89 \mathrm{~mm} ; 0,91 \mathrm{~mm} ; 0,93 \mathrm{~mm} ; 0,94 \mathrm{~mm} ; 0,95 \mathrm{~mm} ; 0,15 \mathrm{~mm} ; 0,16 \mathrm{~mm}$; $0,17 \mathrm{~mm} ; 0,18 \mathrm{~mm} ; 0,19 \mathrm{~mm}, 0,011 \mathrm{gr} ; 0,012 \mathrm{gr} ; 0,013 \mathrm{gr} ; 0,014 \mathrm{gr}$; dan 0,016gr. Penggunaan ekstrak daun $N$. oleander mampu menyebabkan mortalitas $S$. rubrocinctus antara 13,33-76,67\% mulai 24-96 setelah perlakuan. Ekstrak daun N. oleander berpotensi untuk dapat menyebabkan mortalitas $S$. litura. Penggunaan ekstrak daun ini juga dapat menghambat panjang, lebar, dan berat larva.

Kata kunci: Ekstrak Daun Nerium oleander, mortalitas, panjang, lebar, berat, Spodoptera litura 


\section{Pendahuluan}

Nerium oleander merupakan tanaman hias, berasal dari Asia dan memiliki sifat tahan panas dan kekeringan. Tanaman ini dapat ditemukan di berbagai negara seperti India, China, Indonesia, dan beberapa negara Asia lainya. Tanaman ini merupakan perdu, tumbuh tegak, tinggi $2-5 \mathrm{~m}$, berdaun tebal, bertangkai sekitar $1 \mathrm{~cm}$ yang agak membengkok, 3 daun sering tumbuh melingkar, bergetah dan dapat tumbuh pada ketinggian antara 1-700 mdpl. Helaian daun berbentuk lanset dengan ibu tulang daun yang menonjol, ujung dan pangkal daun runcing, tepi rata, warna daun bagian atas hijau tua dan warna daun bagian bawah hijau muda, panjang 7-20 cm, dan lebar 1-3 cm. Antara bunga yang satu dan yang lain memiliki bentuk yang tidak identik. Bunga dalam karangan berbentuk malai di ujung ranting, mahkota berbentuk corong, tabung pada pangkal sempit, berwarna merah muda atau putih. Buah berbentuk lonjong, panjang 7-15 cm, dan pada permukaan luarnya keras dan kering. Cabang tanaman tumbuh secara rutin, tumbuh tegak, warna hijau tidak menyolok, permukaan luarnya tidak ada duri, dan memiliki ketebalan yang cukup. Tanaman ini dapat dibudidayakan di berbagai tempat. Dapat tumbuh di tempat yang teduh atau di bawah sinar matahari penuh, dapat ditanam di tanah liat, tanah pasir, asam, dan basa. Tanaman dapat tumbuh hanya dengan pemupukan satu kali dalam setahun. Untuk perbanyakan tanaman dapat dilakukan melalui stek. Pemanfaatan tanaman $N$. oleander sebagai pengendalian hama belum banyak dilakukan, padahal telah banyak diketahui bahwa tanaman ini mengandung oleandrin yang memiliki sifat insektisida dan antifeedant. Bagian tanaman yang dapat digunakan untuk pengendalian hama antara lain akar, batang, kulit batang, daun, dan bunga, tetapi yang paling sering digunakan adalah pada bagian daunnya, karena memiliki kandungan oleandrin paling tinggi (Dalimartha, 2008).

Spodoptera litura merupakan serangga hama yang memiliki persebaran luas di berbagai tempat di Asia (Hadapad et al., 2001). S. litura bersifat polifag dan memiliki kisaran inang tanaman yang luas, lebih dari 112 tanaman pertanian yang terdiri dari 44 suku (Shingh et al.,
1998). Larva S. litura biasanya menimbulkan kerusakan dengan menyerang pada bagian daun dan bunga (Devanand dan Rani, 2008). S. litura biasanya melakukan penyerangan secara berkelompok. Telur kebanyakan diletakkan secara berkelompok, satu kelompok dapat berisi 350 butir (Pracaya, 2008). Peletakkan telur secara berkelompok ini menyebabkan larva yang baru menetas juga berkelompok dan segera menyebar jika sudah mencapai instar ketiga. Larva instar 1-2 masih bergerombol dan memakan lapisan epidermis daun jarak, sehingga daun menjadi kering, sedangkan larva instar 3-5 sudah terpencar dan memakan semua bagian daun kecuali tulang daun (Sudarmo, 1998).

Pengendalian $S$. litura masih banyak menggunakan insektisida kimia, yang menyebabkan munculnya berbagai dampak negatif seperti pencemaran lingkungan, menimbulkan keracunan pada manusia dan menimbulkan ledakan hama (Dent, 1993; Kurniasih et al., 2003). Oleh karena itu, diperlukan pengembangan alternatif pengendalian $S$. litura yang efisien dan aman dengan pemanfaatan pestisida botani ekstrak daun Nerium oleander. Pemanfaatan ekstrak daun $N$. oleander sebagai pengendali Spodoptera litura belum banyak dikaji. Maka, perlu dikembangkan pemanfaatan ekstrak daun ini sebagai pengendali $S$. litura.

\section{Metode Penelitian}

Penelitian dilaksanakan di Laboratorium Entomologi Balai Penelitian Tanaman Tembakau dan Serat mulai bulan Juni sampai Juli 2009. Pengujian dilakukan terhadap larva $S$. litura instar dua. Daun N. oleander yang masih segar dihaluskan dengan menggunakan blender ditambah air sedikit demi sedikit, sampai betulbetul merata. Cairan bahan tersebut kemudian disaring dengan kain kasa halus dan cairan siap digunakan sebagai bahan pestisida botani. Konsentrasi ekstrak daun $N$. oleander yang digunakan adalah $0 ; 2 \times 10^{5} ; 3 \times 10^{5} ; 4 \times 10^{5}$; dan $5 \times 10^{5} \mathrm{ppm}$. Perlakuan dilakukan dengan metode penyemprotan di dalam spray chamber. Perlakuan disusun dalam rancangan acak lengkap (RAL) dengan ulangan 4 kali. Tiap-tiap ulangan digunakan sebanyak 25 ekor larva. 
Parameter yang diamati antara lain kematian setiap 24, 48, 72, dan 96 jam; panjang, lebar, dan berat larva setelah 96 jam setelah perlakuan. Besarnya lethal concentration ( $L C$ ) dan lethal time (LT) ditentukan berdasarkan analisis probit menggunakan Minitab 14. Persentase kematian, panjang, lebar, dan berat larva dianalisis menggunakan Anava bila terdapat beda nyata dilakukan uji jarak Duncan`s Mutiple Range Test (DMRT) 5\%.

\section{Hasil dan Pembahasan}

Pada Tabel 1 terlihat bahwa pada 96 jam setelah perlakuan ekstrak daun dengan konsentrasi $0 ; 2 \times 10^{5} ; 3 \times 10^{5} ; 4 \times 10^{5}$; dan $5 \times 10^{5}$ ppm mampu menyebabkan mortalitas $S$. litura berturut-turut sebesar $0 ; 48,33 ; 53,33 ; 66,67$ dan $76,67 \%$. Adapun pada 72 jam perlakuan ekstrak daun dengan konsentrasi $0 ; 2 \times 10^{5} ; 3 \times 10^{5} ; 4 \times 10^{5}$; dan $5 \times 10^{5}$ ppm mampu menyebabkan mortalitas S. litura berturut-turut sebesar $0 ; 33,33 ; 36,67$; 43,33; dan 50\%. Pada saat 48 jam setelah perlakuan ekstrak daun dengan konsentrasi 0 ; $2 \times 10^{5} ; 3 \times 10^{5} ; 4 \times 10^{5} ;$ dan $5 \times 10^{5} \mathrm{ppm}$ mampu menyebabkan mortalitas $S$. litura berturut-turut sebesar $0 ; 28,33 ; 35 ; 40$ dan 46,67\%. Pada saat 24 jam setelah perlakuan ekstrak daun dengan konsentrasi $0 ; 2 \times 10^{5} ; 3 \times 10^{5} ; 4 \times 10^{5}$; dan $5 \times 10^{5}$ ppm mampu menyebabkan mortalitas $S$. litura berturut-turut sebesar $0 ; 13,33 ; 21,67 ; 23,33$; dan $31,67 \%$. Berdasarkan hasil pengamatan pada perlakuan konsentrasi menunjukkan bahwa dengan semakin meningkatnya konsentrasi dan waktu perlakuan maka akan meningkatkan persentase kematian larva. Hal ini karena semakin meningkatnya konsentrasi yang digunakan maka racun perut yang masuk ke dalam tubuh akan semakin banyak sehingga larva akan semakin banyak yang mengalami kematian. Menurut Goktas et al., (2007), daun N. oleander merupakan pestisida botani yang betipe sebagai racun perut dan penghambat daya makan larva. Menurut Sodiq (1994), racun perut akan mempengaruhi metabolisme larva setelah memakan racun, kemudian racun akan masuk kedalam tubuh dicerna dalam saluran tengah yang kemudian diedarkan bersama darah. Racun yang terbawa darah akan mempengaruhi sistem saraf larva dan kemudian akan menimbulkan kematian. Dengan semakin lamanya waktu perlakuan maka akan semakin meningkatkan mortalitas larva. Hal ini karena semakin lama waktu perlakuan maka racun perut yang masuk kedalam tubuh akan semakin banyak dan daya kerja racun perut yang ada dalam saluran pencernaan akan semakin cepat sehingga akan meningkatkan mortalitas larva. Menurut Prabowo (2010), penggunaan ekstrak daun Nerium oleander pada 96 jam setelah perlakuan, ekstrak daun dengan konsentrasi $0 ; 7,5 \times 10^{4}$; $1,25 \times 10^{5} ; 2,5 \times 10^{5}$; dan $5 \times 10^{5} \mathrm{ppm}$ mampu menyebabkan mortalitas $S$. rubrocinctus berturut-turut sebesar $16 ; 23 ; 35 ; 43$; dan $49 \%$. Jika dibandingkan dengan penggunaan untuk pengendalian Selenothrips rubrocinctus, ekstrak daun $N$. oleander mampu menyebabkan mortalitas pada larva S.litura yang lebih tinggi.

Pada Tabel 2 terlihat bahwa pada 24 jam setelah perlakuan konsentrasi ekstrak yang dibutuhkan untuk menyebabkan mortalitas $S$. litura 25, 50, dan $95 \%$ berturut-turut sebesar $3,79 \times 10^{5}, 6,22 \times 10^{5}$, dan $1,17 \times 10^{6} \mathrm{ppm}$. Setelah 48 jam kemudian, konsentrasi ekstrak yang dibutuhkan untuk menyebabkan mortalitas $S$. litura 25, 50, dan $95 \%$ berturut-turut sebesar $2,65 \times 10^{5}, 4,69 \times 10^{5}$, dan $9,75 \times 10^{5} \mathrm{ppm}$. Dan pada kondisi 96 jam setelah perlakuan konsentrasi ekstrak yang dibutuhkan untuk menyebabkan mortalitas S. litura 25, 50, dan $95 \%$ berturutturut sebesar $2,35 \times 10^{5}, 4,44 \times 10^{5}$, dan $9,49 \times 10^{5} \mathrm{ppm}$. Semakin lama waktu perlakuan maka konsentrasi ekstrak daun yang dibutuhkan untuk membunuh larva akan semakin sedikit. Karena dengan semakin lamanya waktu perlakuan, racun sudah dapat bekerja dengan baik sehingga dapat menyebabkan kematian larva. Semakin tinggi mortalitas larva maka konsentrasai ekstrak yang dibutuhkan akan semakin banyak. Karena untuk dapat meningkatkan kematian larva maka racun yang dibutuhkan untuk membunuh larva akan semakin banyak. Menurut Kamaraj et al., (2008), penggunaan ekstrak Ocimum canum, Ocimum sanctum and Rhinacanthus nasutus 24 jam setelah perlakuan pada larva instar tiga $S$. litura mempunyai LC50 berturut-turut sebesar 36,46; 68,08 dan 68,84 ppm. Adapun menurut Prabowo (2010), penggunaan ekstrak daun Nerium oleander 72 jam setelah perlakuan pada larva Selenothrips rubrocinctus mempunyai 
$\mathrm{LC}_{25,50 \text {, dan } 95}(\mathrm{ppm})$ berturut-turut sebesar $1,7 \times 10^{6}$, $7,2 \times 10^{5}$, dan $13,1 \times 10^{5} \mathrm{ppm}$. Jika dibandingkan dengan ketiga ekstrak tanaman tersebut, penggunaan ekstrak daun $N$. oleander membutuhkan konsentrasi yang lebih banyak sebaliknya jika dibandingkan dengan penggunaan untuk pengendalian Selenothrips rubrocinctus, ekstrak daun $N$. oleander membutuhkan konsentrasi yang lebih sedikit untuk membunuh $S$. litura.

Pada Tabel 3, terlihat bahwa pada konsentrasi ekstrak daun $N$. oleander $2 \times 10^{5} \mathrm{ppm}$, waktu yang dibutuhkan untuk membunuh larva S. litura $\mathrm{LT}_{25,50,95}$ (hari) berturut-turut sebesar 1, 4, dan 10 hari. Pada penggunaan konsentrasi ekstrak daun $N$. oleander $3 \times 10^{5} \mathrm{ppm}$, waktu yang dibutuhkan untuk membunuh larva $S$. litura $\mathrm{LT}_{25}, 50,95$ (hari) berturut-turut sebesar 1, 4, dan 10 hari. Pada penggunaan konsentrasi ekstrak daun $N$. oleander $4 \times 10^{5} \mathrm{ppm}$, waktu yang dibutuhkan untuk membunuh larva $S$. litura $\mathrm{LT}_{25,50,95}$ (hari) berturut-turut sebesar 1, 3, dan 8 hari. Dan pada penggunaan konsentrasi ekstrak daun $N$. oleander $5 \times 10^{5} \mathrm{ppm}$, waktu yang dibutuhkan untuk membunuh larva $S$. litura $\mathrm{LT}_{25,50,95}$ (hari) berturut-turut sebesar 1, 2, dan 7 hari. Semakin tinggi persentase kematian larva maka akan semakin lama waktu yang dibutuhkan untuk membunuh larva. Hal ini karena reaksi racun dalam tubuh serangga sangat lambat sehingga waktu yang dibutuhkan semakin lama. Menurut Prabowo (2010), pada konsentrasi ekstrak daun $N$. oleander $5 \times 10^{5} \mathrm{ppm}$, waktu yang dibutuhkan untuk membunuh larva Selenothrips rubrocinctus $\mathrm{LT}_{25}, 50,95$ (hari) berturut-turut sebesar 2, 5, dan 11 hari. Jika dibandingkan dengan penggunaan untuk pengendalian Selenothrips rubrocinctus, ekstrak daun $N$. oleander membutuhkan waktu membunuh yang lebih singkat untuk membunuh S.litura

Pada Tabel 4 terlihat bahwa pada 96 jam setelah perlakuan ekstrak daun dengan konsentrasi $0 ; 2 \times 10^{5} ; 3 \times 10^{5} ; 4 \times 10^{5} ;$ dan $5 \times 10^{5}$ ppm mampu menyebabkan panjang, lebar, dan berat larva $S$. litura berturut-turut sebesar $0,89 \mathrm{~mm} ; 0,91 \mathrm{~mm} ; 0,93 \mathrm{~mm} ; 0,94 \mathrm{~mm} ; 0,95 \mathrm{~mm}$; $0,15 \mathrm{~mm} ; 0,16 \mathrm{~mm} ; 0,17 \mathrm{~mm} ; 0,18 \mathrm{~mm} ; 0,19 \mathrm{~mm}$, 0,011gr; 0,012gr; 0,013gr; 0,014gr; dan 0,016gr. Dengan semakin meningkatnya konsentrasi ekstrak daun yang digunakan maka akan menyebabkan semakin pendeknya panjang larva. Menurut Goktas et al., (2007), sifat dari ekstrak daun $N$. oleander yang bersifat penghambat nafsu makan (antifeedant) menyebabkan larva menjadi berkurang nafsu makannya sehingga panjang tubuhnya menjadi pendek. Dengan semakin meningkatnya konsentrasi yang diberikan maka akan menyebabkan semakin pendeknya lebar tubuh, pendeknya panjang tubuh, dan semakin berkurang berat larva. Racun yang terkandung dalam ekstrak daun menyebabkan larva menjadi berkurang nafsu makannya sehingga lebar dan panjang tubuhnya menjadi sempit dan berat larva menjadi berkurang.

Tabel 1. Pengaruh ekstrak daun N. oleander terhadap persentase mortalitas larva S. litura.

\begin{tabular}{|c|c|c|c|c|}
\hline \multirow[b]{2}{*}{ Konsentrasi (ppm) } & \multicolumn{4}{|c|}{ Rata-rata Persentase Kematian (\%) } \\
\hline & $\begin{array}{c}\text { 24 Jam setelah } \\
\text { Perlakuan* }\end{array}$ & $\begin{array}{c}48 \text { Jam setelah } \\
\text { Perlakuan }\end{array}$ & $\begin{array}{c}72 \text { Jam setelah } \\
\text { Perlakuan }\end{array}$ & $\begin{array}{c}96 \text { Jam setelah } \\
\text { Perlakuan }\end{array}$ \\
\hline 500 & $31,67 \mathrm{c}$ & $46,67 \mathrm{c}$ & $50,00 \mathrm{c}$ & $76,67 \mathrm{c}$ \\
\hline 400 & $23,33 \mathrm{~b}$ & $40,00 \mathrm{~b}$ & $43,33 \mathrm{~b}$ & $66,67 \mathrm{~b}$ \\
\hline 300 & $21,67 \mathrm{~b}$ & $35,00 \mathrm{ab}$ & $36,67 \mathrm{ab}$ & $53,33 \mathrm{ab}$ \\
\hline 200 & $13,33 \mathrm{a}$ & $28,33 \mathrm{a}$ & $33,33 \mathrm{a}$ & $48,33 \mathrm{a}$ \\
\hline 0 & $0 \mathrm{~d}$ & $0 \quad \mathrm{~d}$ & $0 \mathrm{~d}$ & $0 \mathrm{~d}$ \\
\hline
\end{tabular}

* Angka yang diikuti huruf yang sama dalam kolom yang sama tidak berbeda nyata menurut uji Duncan 5\%

Tabel 2. Lethal concentration (LC) ekstrak daun N. oleander terhadap larva S. litura.

\begin{tabular}{|c|c|c|c|c|}
\hline \multirow[b]{2}{*}{$\begin{array}{c}\text { Persentase Kematian } \\
\text { Larva }(\%)\end{array}$} & \multicolumn{4}{|c|}{ Lethal Concentration (ppm) } \\
\hline & $\begin{array}{l}\text { 24 Jam setelah } \\
\text { Perlakuan }\end{array}$ & $\begin{array}{l}48 \text { Jam setelah } \\
\text { Perlakuan }\end{array}$ & $\begin{array}{c}72 \text { Jam setelah } \\
\text { Perlakuan }\end{array}$ & $\begin{array}{c}96 \text { Jam setelah } \\
\text { Perlakuan }\end{array}$ \\
\hline $95 \%$ & $1,17 \times 10^{6}$ & $9,75 \times 10^{5}$ & $9,49 \times 10^{5}$ & $8,45 \times 10^{5}$ \\
\hline $50 \%$ & $6,22 \times 10^{5}$ & $4,69 \times 10^{5}$ & $4,44 \times 10^{5}$ & $2,39 \times 10^{5}$ \\
\hline $25 \%$ & $3,79 \times 10^{5}$ & $2,65 \times 10^{5}$ & $2,35 \times 10^{5}$ & $0,46 \times 10^{5}$ \\
\hline
\end{tabular}


Tabel 3. Lethal time (LT) ekstrak daun N. oleander terhadap larva S. litura.

\begin{tabular}{ccccc}
\hline \hline Lethal Time & \multicolumn{4}{c}{ Konsentrasi ekstrak daun $\boldsymbol{N}$. oleander (ppm) } \\
\cline { 2 - 5 } & $2 \times 10^{5}$ & $3 \times 10^{5}$ & $4 \times 10^{5}$ & $5 \times 10^{5}$ \\
\hline \hline $\mathrm{LT}_{25}$ (hari) & 1 & 1 & 3 & 1 \\
$\mathrm{LT}_{50}$ (hari) & 4 & 4 & 8 & 2 \\
$\mathrm{LT}_{95}$ (hari) & 10 & 10 & 7 \\
\hline \hline
\end{tabular}

Tabel 4. Pengaruh ekstrak $N$. oleander terhadap perkembangan larva $S$. litura setelah 96 jam setelah perlakuan.

\begin{tabular}{|c|c|c|c|}
\hline \multirow[b]{2}{*}{ Konsentrasi (ppm) } & \multicolumn{3}{|c|}{ Perkembangan larva setelah 96 jam setelah perlakuan } \\
\hline & $\begin{array}{c}\text { Rerata panjang larva } \\
(\mathbf{m m})\end{array}$ & $\begin{array}{c}\text { Rerata lebar larva } \\
(\mathbf{m m})\end{array}$ & $\begin{array}{c}\text { Rerata berat larva } \\
\text { (gr) }\end{array}$ \\
\hline $5 \times 10^{5}$ & $0,89 \mathrm{a}$ & $0,15 \mathrm{a}$ & $0,011 \mathrm{a}$ \\
\hline $4 \times 10^{5}$ & $0,91 \mathrm{~b}$ & $0,16 \mathrm{~b}$ & $0,012 \mathrm{~b}$ \\
\hline $3 \times 10^{5}$ & $0,93 \mathrm{c}$ & $0,17 \mathrm{c}$ & $0,013 \mathrm{c}$ \\
\hline $2 \times 10^{5}$ & $0,94 \mathrm{~d}$ & $0,18 \mathrm{~d}$ & $0,014 \mathrm{~d}$ \\
\hline 0 & $0,95 \mathrm{e}$ & $0,19 \mathrm{e}$ & $0,016 \mathrm{e}$ \\
\hline
\end{tabular}

*Angka yang diikuti huruf yang sama dalam kolom yang sama tidak berbeda nyata menurut uji Duncan 5\%

\section{Simpulan dan Saran}

\section{Simpulan}

Penggunaan ekstrak daun $N$. oleander mampu menyebabkan mortalitas $S$. rubrocinctus antara $13,33-76,67 \%$ mulai 24-96 setelah perlakuan. Ekstrak daun N. oleander berpotensi untuk dapat menyebabkan mortalitas S. litura. Penggunaan ekstrak daun ini juga dapat menghambat pertumbuhan larva.

\section{Saran}

Perlu dilakukan penelitian lain tentang pengaruh ekstrak daun $N$. oleander terhadap hama selain $S$. litura, sehingga dapat diketahui pengaruh ekstrak daun terhadap hama selain $S$. litura.

\section{Daftar Pustaka}

Dalimartha, S. 2008. Atlas Tumbuhan Obat Indonesia: menguak kekayaan tumbuhan obat Indonesia. Niaga Swadaya. Jakarta.

Dent, D. 1993. Insect Pest Management. CAB International. Oxon.Uk.

Devanand, Peta dan Pathipati, U.R. 2008. Biological potency of certain plant extracts in management of two lepidopteran pests of Ricinus communis L. J. of Biopesticides, 1 (2): 170-176 (2008).

Goktas, O., Mammadov, R., Duru, M.E., Ozen, E. dan Colak, A.M. 2007. Application of extracts from the poisonous plant, Nerium Oleander L., as a wood preservative. African J. of Biotechnology, 6 (17): 2000-2003.

Hadapad, A., Chaudhari, C.S., Kulye, M., Chaudele, A.G. dan Salunkhe, G.N. 2001. Studies on chitin synthesis inhibitors against gram pod borer, Helicoverpa armigera (Hub.). J. of Natcon, 13 (2): 137-140.

Kamaraj, C., Abdul, R.A. dan Bagavan, A. 2008. Antifeedant and larvicidal effects of plant extracts against Spodoptera litura (F.), Aedes aegypti L. and Culex quinquefasciatus Say. J. Parasitology, 103 (2): 325-331.

Kurniasih, M., Prihantini, N.B. dan Nurtiyani, E. 2003. Pertumbuhan Mikroalga Chlamydomonas dalam Medium Beneck dan Air Tanah yang Mengandung Insektisida Berbahan Aktif Klorpirifos. Biota, VIII (1): 39-44.

Pracaya. 2008. Hama dan Penyakit Tanaman. Penebar Swadaya. Jakarta.

Prabowo, H. 2010. Toksisitas Ekstrak Daun Nerium oleander L. terhadap Selenothrips rubrocinctus Giard. Prosiding seminar nasional jarak pagar ke V. Balai penelitian tanaman tembakau dan serat. Malang.

Singh, A.K., Parasnath dan Ojha, J.K. 1998. Antifeeding response of some plant extract against Spodoptera litura (Fab.) of groundnut. Indian J. of Applied Entomology, 12: 9-13.

Sodiq, M. 1994. Tosikologi Pestisida. Universitas Pembangunan Nasional "Veteran" Surabaya. Fakultas Pertanian.

Sudarmo, S. 1998. Pengendalian Serangga Hama Kacang Tanah. Penerbit Kanisius. Yogyakarta. 